\title{
"Emergence of Non albicans Candida as potential pathogen --- Change in spectrum poses therapeutic challenge"
}

\author{
Piyali Halder ${ }^{1}$, Reena Ray $\left(\right.$ Ghosh) ${ }^{2}$, Moumita Sarker ${ }^{3}$, \\ Prabir kumar Mukherjee ${ }^{4}$. \\ 1,3 Postgraduates (MD Micobiology), R.G.Kar Medical College \& Hospital. \\ ${ }^{2}$ Associate Professor, Dept. of Microbiology, R.G.Kar Medical College \& Hospital. \\ 4Professor,Dept.of Microbiology, R.G.Kar Medical College \& Hospital.
}

\begin{abstract}
:
Introduction: The last two decades have seen a significant rise in infections caused by Candida species in various clinical conditions. Candida albicans is the most frequently isolated yeasts in clinical laboratory, but now there is a predominant rise in infections caused by non-albicans Candida.. Differentiating among Candida species in laboratory is very important because of the differences in the virulence of the species and in their susceptibility to anti-fungal drugs.

Aims And Objective: The aim of the present study is to isolate and speciate Candida spp. from various clinical specimens, processed in our laboratory and to detect their antifungal susceptibility pattern.

Materials And Methods: The study was carried out in The Department of Microbiology, R.G.Kar Medical College and Hospital, Kolkata for the period of 1 yr. A Total 92 Candida isolates were obtained from various clinical samples were included in the study. The isolates were identified up to species level by standard mycological procedure. Antifungal susceptibility testing of the yeast isolates were assessed by Kirby Bauer disc diffusion method following CLSI guidelines M 44A against Amphotericin B and Azole group of antifungals like Fluconazole, ketoconazole, Itraconazole, and Voriconazole.

Result: In the study, total 10 species of Candida were isolated from various clinical samples, of which Candida tropicalis was the commonest species isolated 30 (32.6\%).The highest number of Candida isolates were obtained from Blood-29 (31.52\%).Among the five antifungal drugs tested (Amphotericin B, Ketoconazole, Fluconazole, Itraconazole and Voriconazole), maximum resistance was seen with Fluconazole (29\%). Fluconazole resistant was more in NAC species than Candida albicans.

Conclusion: Early speciation of Candida isolates along with their antifungal susceptibility tests not only will restrict the empirical use of the antifungal agents but also greatly influence the treatment options for the clinicians and thus optimum benefit of the patients can be achieved.
\end{abstract}

\section{Introduction}

Fungi, which were once studied only as "microbiological curiosities" with less or no pathogenic role have emerged as important cause of opportunistic and health-care associated infections ${ }^{1}$. Among various pathogenic species of fungi, Candida is the most prominent cause of fungal infections ${ }^{2}$. Although Candida albicans is the most prevalent species involved in both mucocutaneous and disseminated infections, the incidence of candidiasis due to non-albicans Candida (NAC) is increasing ${ }^{3}$.The clinical manifestations of infections caused by different members of NAC spp. are usually indistinguishable, but several NAC are inherently resistant or acquire resistance, or both, to commonly used antifungal drugs ${ }^{2}$.

Therefore, the potential clinical importance of species-level identification has been recognized as the need of the time as Candida species differ in the expression of virulence factors and antifungal susceptibility ${ }^{4}$ The aim of the present study was to identify the spectrum of Candida species in clinical infections, risk factors associated with it and to identify their sensitivity pattern to available antifungal agents.

\section{Materials And Methods}

The study was carried out in The Department of Microbiology, R.G. Kar Medical College and Hospital, Kolkata during a period of one year.

A Total 92 Candida strains were isolated were subjected to speciation and antifungal susceptibility testing.

Source of Candida strains: A total of 92 Candida isolates from various clinical samples --Blood, urine, high vaginal swab, sputum, deep tracheal aspirate, bronchoalveolar lavage, nail clippings, wound swab, plastic devices(Foley's catheters tip, endotracheal tube tip, central line tip etc.),processed as routine work in the microbiology laboratory, were included in the study. The repeated isolation of Candida species from these clinical specimens was considered significant. 
“Emergence of Non albicans Candida as potential pathogen --- Change in spectrum ....

\section{Candida sub-culture}

The Candida strains obtained from different clinical samples were subjected to subculture to get fresh culture to proceed to the next step of species identification and antifungal susceptibility testing. The sub culture was performed on SDCA tubes and the tubes were incubated at $37^{\circ} \mathrm{C}$ for $24 \mathrm{hrs}$ and these fresh Candida culture was used for further testing.

Growth of Candida was confirmed by the yeast like colony grown on culture showing budding yeast cells in Gram's staining and a negative urease test. The LPCB mount was also prepared from the colonies to examine for presence of yeast cells and pseudohyphae.

\section{Species identification}

Speciation of Candida is done on the basis of colony characteristics ,Germ tube test

Microscopic morphology on corn meal agar ,HiCHROM Candida (HIMEDIA Laboratories, Mumbai), Sugar fermentation test and Sugar assimilation test. All tests are performed as per standard laboratory procedures and following manufacturer's guidelines.

\section{Antifungal Susceptibility Testing:}

Antifungal susceptibility testing of the yeast isolates was assessed using the Disc diffusion method according to CLSI guidelines. The discs were supplied by Hi-Media, Mumbai. Muller-Hinton agar supplemented with $2 \%$ glucose and $0.5 \mu \mathrm{g} / \mathrm{ml}$ methylene blue was used for the sensitivity testing. Kirby Bauer disc diffusion method was used in the present study. The antifungal agents used for disc method are: Amphotericin B, Ketoconazole, Fluconazole, Itraconazole, Voriconazole.

\section{Preparation of inoculum for the Disc diffusion test:}

Using a sterile inoculating loop, distinct colonies of yeast from the SDA plates were transferred into $2 \mathrm{ml}$ of normal saline in a test tube. The colonies were emulsified in the saline solution to form a suspension of turbidity equivalent to $0.5 \mathrm{McF}$ arland.

\section{Inoculation of the agar plates:}

A sterile cotton swab was dipped into the inoculum already prepared. Using the cotton swab, the dried surface of the Mueller-Hinton agar (supplemented with glucose and methylene blue) was inoculated with the test organism. The plates were left for 5 minutes to allow for any surface moisture to be absorbed before the drug impregnated discs were applied. Using sterile

The plates were examined after 20 to $24 \mathrm{hrs}$ of incubation. The diameters of zones of complete inhibition were measured to the nearest whole numbers in millimeters using meter rule and recorded. The diameters of the zones of inhibition obtained were compared with the standard zones interpretive breakpoints published by CLSI M44-A2 guidelines.

\section{Results}

A total of 92 clinical isolates of Candida from various clinical specimens were processed during the study period.Maximum number of Candida isolates were obtained from Blood-29(31.52\%),followed by Nail clippings-19 (20.65\%), Respiratory specimens-16 (17.39\%),Urine-14 (15.21\%). Table 1 shows distribution of different clinical samples from which Candida strains were isolated:

Table 1: Distribution of Candida species in different clinical samples

\begin{tabular}{|l|c|c|}
\hline CLINICAL SPECIMEN & NUMBER OF ISOLATES & PERCENTAGE \\
\hline BLOOD & 29 & $31.5 \%$ \\
\hline NAIL CLIPPINGS & 19 & $20.6 \%$ \\
\hline URINE & 14 & $15.2 \%$ \\
\hline SPUTUM & 7 & $7.6 \%$ \\
\hline DTS & 4 & $4.34 \%$ \\
\hline BAL FLUID & 4 & $4.34 \%$ \\
\hline PLEURAL FLUID & 1 & $1.08 \%$ \\
\hline WOUND SWAB/PUS & 5 & $5.4 \%$ \\
\hline VAGINAL SWAB & 4 & $4.34 \%$ \\
\hline NASOLABIAL MASS & 2 & $2.17 \%$ \\
\hline ET TUBE & 1 & $1.08 \%$ \\
\hline SUCTION TIP CATHETER & 1 & $1.08 \%$ \\
\hline
\end{tabular}


Fig 2: Distribution of patients according to age

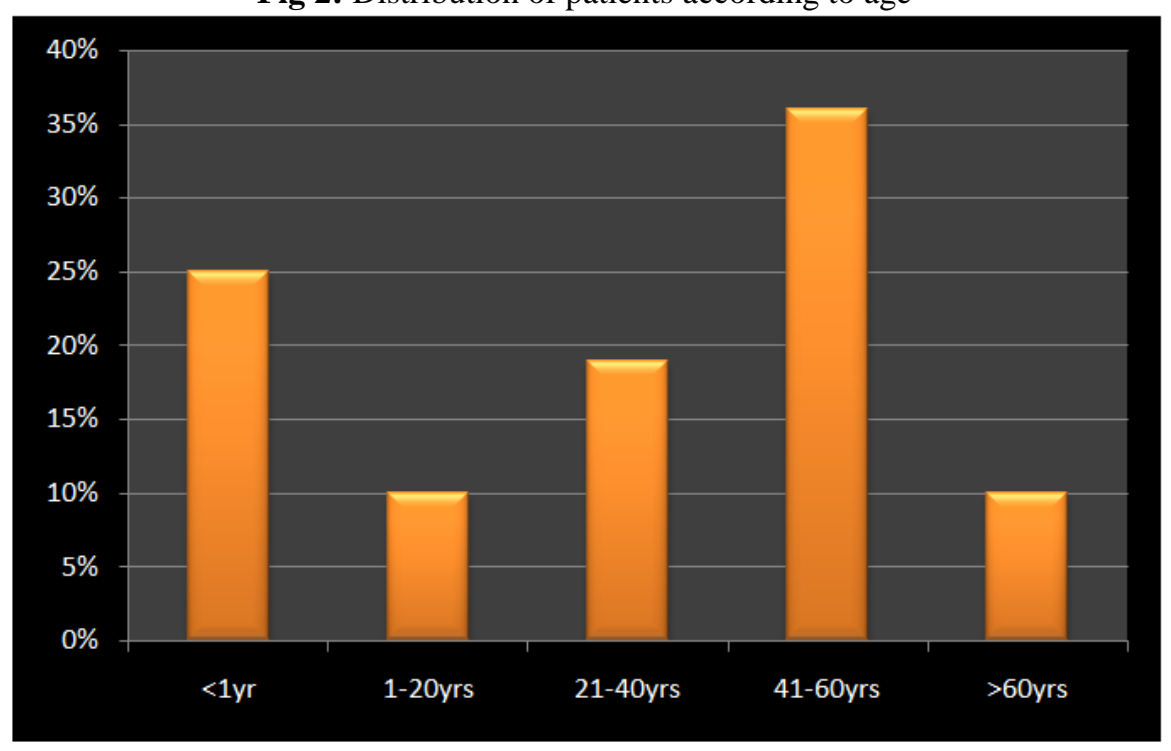

Fig 2 shows Age distribution of patients from whom Candida species were isolated. The highest number of isolates were from the age group 41-60 yrs 33(36\%), followed by 0 to $1 \mathrm{yr}-23(25 \%), 20-40 \mathrm{yrs} 18(19.5 \%), 1-20$ yrs $9(9.7 \%)$ and more than 60 yrs $9(9.7 \%)$.

Fig 1: Species distribution of Candida isolates

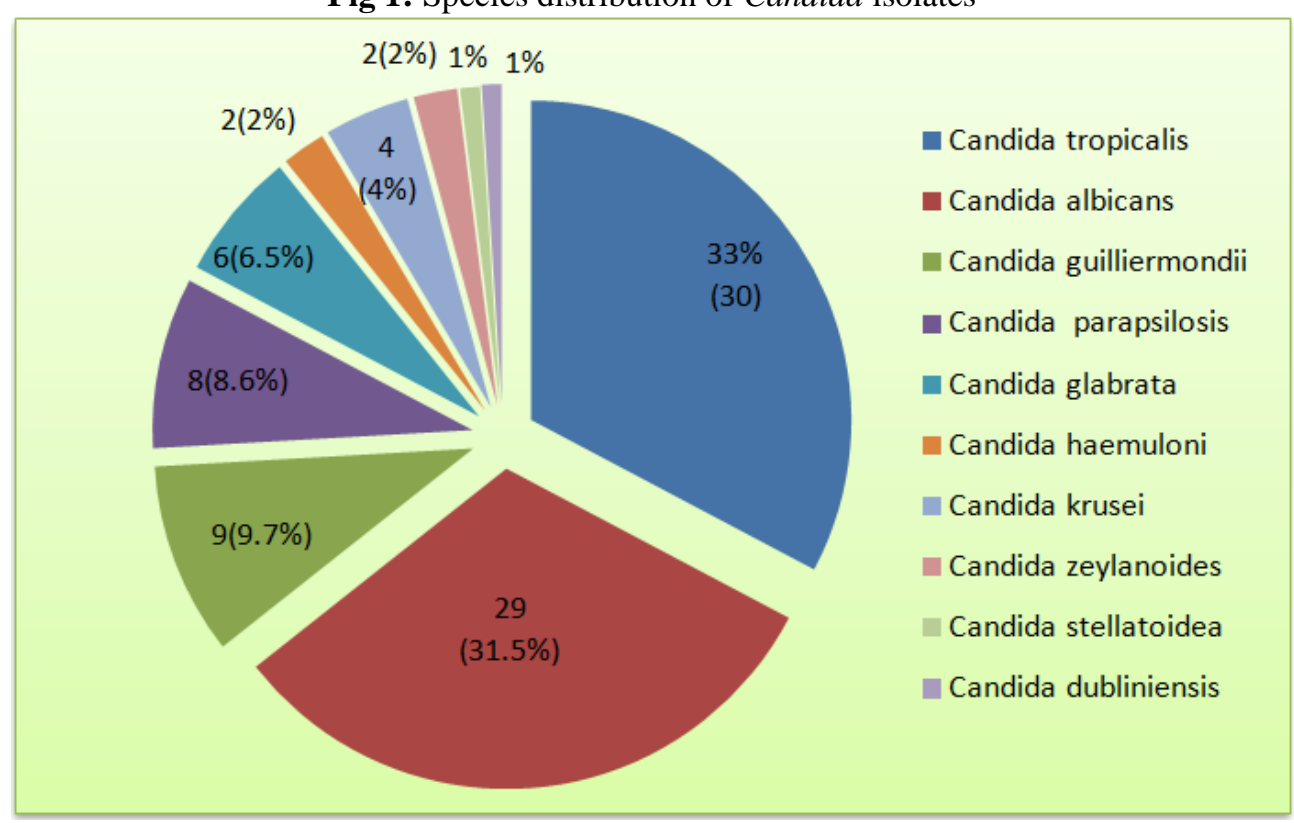

Table 2: Distribution of predisposing factors in patients with Candida infection.

\begin{tabular}{|l|l|}
\hline Predisposing factors & No. of patients(\%) \\
\hline Diabetes mellitus & $19(20.65 \%)$ \\
\hline Presence of in-situ device & $57(61.9 \%)$ \\
\hline Hospital stay(>10days) & $21(22.82 \%)$ \\
\hline Broad-spectrum antibiotic & $74(80.43 \%)$ \\
\hline Prematurity/low birth weight & $9(9.78 \%)$ \\
\hline Radiotherapy/chemotherapy & $4(4.34 \%)$ \\
\hline
\end{tabular}


"Emergence of Non albicans Candida as potential pathogen --- Change in spectrum ....

Table 3: Distribution of different species of Candida among various clinical specimens.

\begin{tabular}{|c|c|c|c|c|c|c|c|c|}
\hline $\begin{array}{l}\text { Clinical } \\
\text { specimen }\end{array}$ & $\begin{array}{l}\text { Candida } \\
\text { tropicalis }\end{array}$ & $\begin{array}{l}\text { Candida } \\
\text { albicans }\end{array}$ & $\begin{array}{l}\text { Candida } \\
\text { parapsilosis }\end{array}$ & $\begin{array}{l}\text { Candida } \\
\text { glabrata }\end{array}$ & $\begin{array}{l}\text { Candida } \\
\text { krusei }\end{array}$ & $\begin{array}{l}\text { Candida } \\
\text { guillier } \\
\text { mondii }\end{array}$ & $\begin{array}{l}\text { Candida } \\
\text { haemu } \\
\text { lonii }\end{array}$ & $\begin{array}{l}\text { OTHERS } \\
\text { (C.dubliniensis, } \\
\text { C.zeylanoides, } \\
\text { C.stellatoidea) }\end{array}$ \\
\hline Blood & $\begin{array}{c}5 \\
(17.2 \%)\end{array}$ & $\begin{array}{l}6 \\
(20.7 \%)\end{array}$ & $\begin{array}{l}3 \\
(10.3 \%)\end{array}$ & $\begin{array}{l}3 \\
(10.3 \%)\end{array}$ & $\begin{array}{l}3 \\
(10.3 \%)\end{array}$ & $\begin{array}{l}7 \\
(24 \%)\end{array}$ & $\begin{array}{l}2 \\
(6.9 \%)\end{array}$ & -- \\
\hline Nail & $\begin{array}{l}7 \\
(36.8)\end{array}$ & $\begin{array}{l}7 \\
(36.8 \%)\end{array}$ & $\begin{array}{l}2 \\
(10.5 \%)\end{array}$ & -- & -- & $\begin{array}{l}1 \\
(5.2 \%)\end{array}$ & -- & $\begin{array}{l}2 \\
(10.5 \%)\end{array}$ \\
\hline Urine & $\begin{array}{l}10 \\
(71.4 \%)\end{array}$ & $\begin{array}{l}2 \\
(14.3 \%)\end{array}$ & -- & $\begin{array}{l}1 \\
(7.14 \%)\end{array}$ & -- & -- & -- & $\begin{array}{l}1 \\
(7.14 \%)\end{array}$ \\
\hline DTS & -- & $\begin{array}{l}3 \\
(75 \%)\end{array}$ & -- & $\begin{array}{l}1 \\
(25 \%)\end{array}$ & -- & -- & -- & -- \\
\hline $\begin{array}{l}\text { BAL } \\
\text { Fluid }\end{array}$ & -- & $\begin{array}{l}3 \\
(75 \%) \\
\end{array}$ & -- & -- & -- & $\begin{array}{l}1 \\
(25 \%)\end{array}$ & - & -- \\
\hline Sputum & $\begin{array}{l}4 \\
(57 \%)\end{array}$ & $\begin{array}{l}3 \\
(42.8 \%)\end{array}$ & -- & -- & -- & -- & -- & -- \\
\hline $\begin{array}{l}\text { Pleural } \\
\text { fluid }\end{array}$ & $\begin{array}{l}1 \\
(100 \%)\end{array}$ & -- & -- & -- & -- & -- & -- & -- \\
\hline $\begin{array}{l}\text { Wound } \\
\text { swab/Pus }\end{array}$ & -- & $\begin{array}{l}3 \\
(75 \%)\end{array}$ & -- & $\begin{array}{l}1 \\
(25 \%)\end{array}$ & -- & -- & -- & -- \\
\hline Vaginal swab & $\begin{array}{l}3 \\
(75 \%)\end{array}$ & $\begin{array}{l}1 \\
(25 \%)\end{array}$ & -- & -- & -- & -- & -- & -- \\
\hline $\begin{array}{l}\text { Nasolabial } \\
\text { mass }\end{array}$ & -- & -- & $1(25 \%)$ & $1(25 \%)$ & -- & -- & -- & -- \\
\hline ET Tube & -- & $1(100 \%)$ & -- & -- & -- & -- & -- & -- \\
\hline $\begin{array}{l}\text { Central line } \\
\text { tube }\end{array}$ & -- & -- & $1(100 \%)$ & -- & -- & -- & -- & -- \\
\hline Suction tube & -- & -- & $1(100 \%)$ & -- & -- & -- & -- & -- \\
\hline
\end{tabular}

Table 4: Antifungal susceptibility pattern of different Candida species

\begin{tabular}{|c|c|c|c|c|c|c|c|c|c|c|}
\hline $\begin{array}{l}\text { ANTIFUNGAL } \\
\text { DRUGS }\end{array}$ & $\begin{array}{l}\text { C. } \\
\text { albicans }\end{array}$ & $\begin{array}{l}C \\
\text { tropicalis }\end{array}$ & $\begin{array}{l}\text { C } \\
\text { parapsilosis }\end{array}$ & $\begin{array}{l}\text { C } \\
\text { guilliermondii }\end{array}$ & $\begin{array}{l}\text { C } \\
\text { glabrata }\end{array}$ & $\begin{array}{l}\text { C } \\
\text { Krusei }\end{array}$ & \begin{tabular}{|l}
$C$ \\
haemulonii
\end{tabular} & $\begin{array}{l}\text { C } \\
\text { dubliniensis }\end{array}$ & Cstellatoidea & $\begin{array}{l}\text { C } \\
\text { zeylanoides }\end{array}$ \\
\hline \multicolumn{11}{|l|}{ Amphotericin B } \\
\hline Sensitive & $26(90 \%)$ & $27(90 \%)$ & $7(87.5 \%)$ & $7(78 \%)$ & $4(67 \%)$ & $4(100 \%)$ & 0 & $1(100 \%)$ & $1(100 \%)$ & $2(100 \%)$ \\
\hline $\begin{array}{l}\text { Dose-dependent } \\
\text { sensitive }\end{array}$ & $3(10 \%)$ & $1(3.3 \%)$ & 0 & 0 & $2(33 \%)$ & 0 & $2(100 \%)$ & 0 & 0 & 0 \\
\hline Resistant & 0 & $2(6.7 \%)$ & $1(12.5 \%)$ & $2(22 \%)$ & 0 & 0 & 0 & 0 & 0 & 0 \\
\hline \multicolumn{11}{|l|}{ Fluconazole } \\
\hline Sensitive & $20(69 \%)$ & $17(57 \%)$ & $6(75 \%)$ & $6(67 \%)$ & $1(17 \%)$ & $1(25 \%)$ & 0 & $1(100 \%)$ & $1(100 \%)$ & $1(50 \%)$ \\
\hline $\begin{array}{l}\text { Dose Dependent } \\
\text { sensitive }\end{array}$ & $4(14 \%)$ & $5(16 \%)$ & $1(12.5 \%)$ & 0 & $1(17 \%)$ & 0 & 0 & 0 & 0 & 0 \\
\hline Resistant & $5(17 \%)$ & $8(27 \%)$ & $1(12.5 \%)$ & $3(3.3 \%)$ & $4(66 \%)$ & $3(75 \%)$ & $2(100 \%)$ & 0 & 0 & $1(50 \%)$ \\
\hline \multicolumn{11}{|l|}{ Ketoconazole } \\
\hline Sensitive & $22(76 \%)$ & $20(67 \%)$ & $6(75 \%)$ & $889 \%)$ & $4(67 \%)$ & $4(100 \%)$ & 0 & $1(100 \%)$ & $1(100 \%)$ & $2(100 \%)$ \\
\hline $\begin{array}{l}\text { Dose dependent } \\
\text { sensitive }\end{array}$ & $3(10 \%)$ & $4(13 \%)$ & $2(25 \%)$ & 0 & $1(17 \%)$ & 0 & $1(50 \%)$ & 0 & 0 & 0 \\
\hline Resistant & $4(14 \%)$ & $4(20 \%)$ & 0 & $1(11 \%)$ & $1(16 \%)$ & 0 & $1(50 \%)$ & 0 & 0 & 0 \\
\hline \multicolumn{11}{|l|}{ Itraconazole } \\
\hline Sensitive & $22(76 \%)$ & $19(63 \%)$ & $6(75 \%)$ & $7(78 \%)$ & 0 & $1(12.5 \%)$ & 0 & $1(100 \%)$ & $1(100 \%)$ & $1(50 \%)$ \\
\hline $\begin{array}{l}\text { Dose-dependent } \\
\text { sensitive }\end{array}$ & $3(10 \%)$ & $5(17 \%)$ & $1(12.5 \%)$ & $1(11 \%)$ & $3(50 \%)$ & $1(12.5 \%)$ & $1(50 \%)$ & 0 & 0 & 0 \\
\hline Resistant & $4(14 \%)$ & $6(20 \%)$ & $1(12.5 \%)$ & $1(11 \%)$ & $3(50 \%)$ & $2(50 \%)$ & $1(50 \%)$ & 0 & 0 & $1(50 \%)$ \\
\hline \multicolumn{11}{|l|}{ Voriconazole } \\
\hline Sensitive & $28(96.5 \%)$ & $28(93 \%)$ & $8(100 \%)$ & $9(100 \%)$ & $5(83 \%)$ & $3(75 \%)$ & $2(100 \%)$ & $1(100 \%)$ & $1(100 \%)$ & $2(100 \%)$ \\
\hline $\begin{array}{l}\text { Dose Dependent } \\
\text { sensitive }\end{array}$ & $1(3.5 \%)$ & $1(3.3 \%)$ & 0 & 0 & 0 & 0 & 0 & 0 & 0 & 0 \\
\hline Resistant & 0 & $1(3.3 \%)$ & 0 & 0 & $1(17 \%)$ & $1(25 \%)$ & 0 & 0 & 0 & 0 \\
\hline
\end{tabular}


Fig 11: Resistance pattern of the Candida isolates to antifungals used

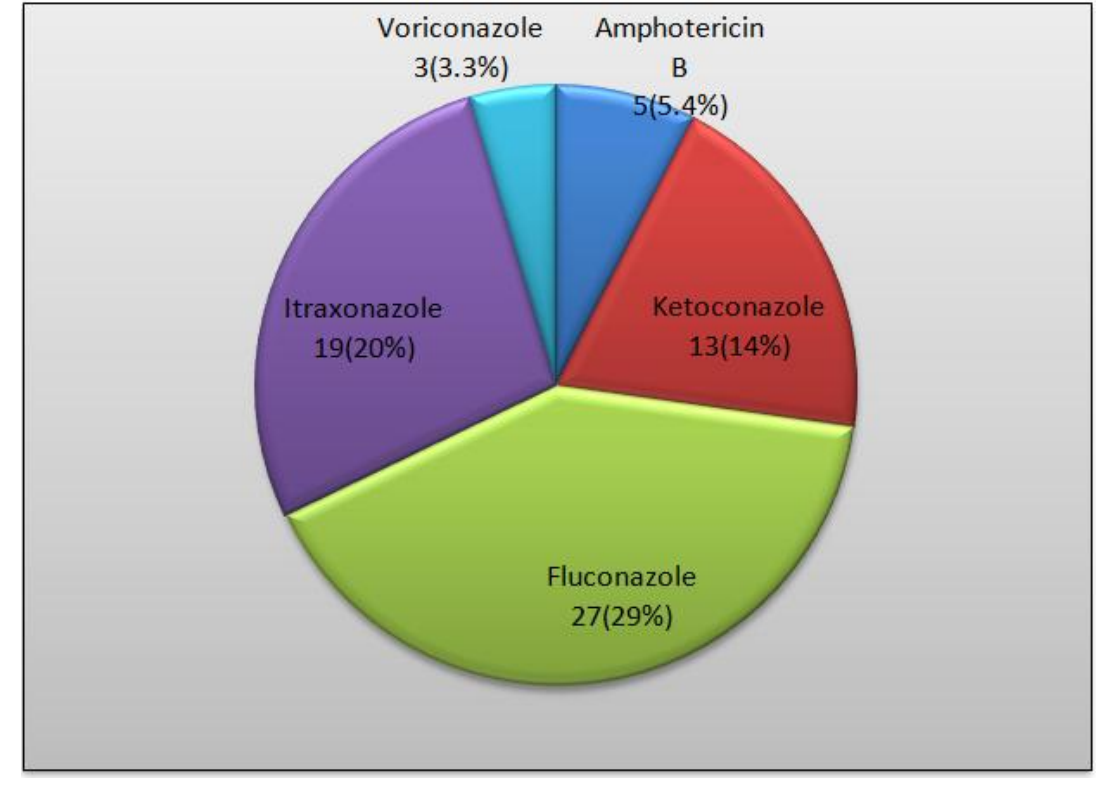

In the present study, maximum resistance was seen with Fluconazole (29\%), followed by Itraconazole (20\%).On the other hand resistance to Voriconazole and Amphotericin B were only $3.3 \%$ and $5.4 \%$ respectively.

\section{Discussion}

A total of 92 Candida isolates from various clinical specimens were included in this study, of which highest number of isolates $(31.5 \%)$ were recovered from blood, followed by nail clippings (20.65\%) and urine (15.2\%).Data from surveillance and control of pathogens of epidemiological importance (SCOPE) surveillance system confirms that Candida species have become the fourth leading cause of blood stream infections. Out of 29 blood culture that showed presence of Candida,24 were from NICU and SNCU. Thus the neonates were at higher risk of developing candidemia ${ }^{5}$. Study of Tavleen $\mathrm{Jaggi}^{6}$ et al also had similar finding, where Candida was mainly isolated from blood (33.6\%) and respiratory samples (20\%).

Our study showed that non-albicans Candida were isolated at a higher rate (68.5\%) than C. albicans (31.5\%) which was in agreement with the findings of the study by Mokaddas et. al. They also showed the higher isolation of non-albicans Candida (60.5\%) than C. albicans $(39.5 \%)^{7}$. In this study, Candida tropicalis was the most common isolate $(32.6 \%)$, which is concordant with other studies of Lata R Patel et al. ${ }^{8}(C$. tropicalis47.4\%), V.Manchandaet al. ${ }^{9}$ (C.tropicalis-55.03\%) and Kashid RA et al ${ }^{10}$ (C. tropicalis $46.25 \%$ ).

In present study prolonged broad spectrum antibiotic use was the most important risk factor, associated with $74(80 \%)$ of the cases. The most important effect of antibiotics is the elimination and alteration of the bacterial flora that holds the population of Candida in check. Arora D et $\mathrm{al}^{11}$ also reported that, $35 \%$ of Candidiasis was due to prolonged use of antibiotics. Presence of in-situ device was another important risk factor in our study. It was associated with $61.9 \%$ of cases. Due to ability of the Candida to form biofilm over indwelling devices, Candidiasis commonly occurs in patients with these devices.Study of Sagarika Pradhan et $\mathrm{al}^{12}$ also found presence of indwelling catheter as a risk factor where indwelling catheter was associated with $89.3 \%$ of cases.

In our study resistance of Candida against Fluconazole was more (29\%) in comparison to other antifungals used in this study. The study by Dharwad et $a l^{13}$ and Biradar et $a{ }^{14}$ also had similar finding. The higher degree of resistance to fluconazole might be due to widespread and indiscriminate use of this drug for extended periods. Moreover few species of non albicans Candida are intrinsically resistant to azoles which might be a contributing factor to this fluconazole resistance.

Maximum resistance to fluconazole was shown by Candida krusei (75\%),followed by Candida glabrata $(66.7 \%)$ and Candida tropicalis $(26.7 \%)$ whereas study by Dharwad et al. ${ }^{13}$ reported fluconazole resistance in C. krusei, C. glabrata and C. tropicalis was $60 \%, 33.3 \%$ and $25 \%$ respectively.

Over all resistance of Candida to Amphotericin B in the present study was 5.4\%, which was comparable to other studies like study by Dharwad et al ${ }^{13}$ and Sagarika Pradhan et al. ${ }^{12}$ where $8 \%$ and $6.4 \%$ resistance was reported respectively.

In the present study there was no resistance for voriconazole detected for C. albicans whereas $C$. tropicalis showed a resistance of $3.3 \%$ to voriconazole. Overall resistance to voriconazole was $3.3 \%$. Results 
from the latest ARTEMIS DISK Global Antifungal Surveillance Study of Candida species also shows 95\% susceptibility for voriconazole ${ }^{15}$, whereas study of Rekha I.R et al ${ }^{16}$ showed $100 \%$ sensitivity to voriconazole.

\section{Conclusion}

Just a decade ago, Candida albicans was considered as the most pathogenic member of the genus Candida. The isolation of NAC species from clinical samples was ignored as the isolates were considered as non-pathogenic commensals or contaminants. Our study documents a shift from Candida albicans to NAC species as a cause of Candidiasis. An increase in the predisposing factors has resulted in an increasing incidence of non albicans Candida infections. Some of the non albicans Candida species are intrinsically resistant to commonly used antifungal drugs. Therefore, species identification of Candida isolates along with their antifungal susceptibility tests not only restrict the empirical use of the antifungal agents but also greatly influence the treatment options for the clinicians that might have a positive effect in the treatment outcome.

\section{References}

[1]. Chakrabarti A,Kaur R,Das S.Molecular methods for diagnosis of fungal infections.Indian J Med Microbial 2000;18:146-52

[2]. Sullivan, D., Henman, M., Moran, G., et al. 1996. Molecular genetic approaches to identification, epidemiology and taxonomy of non-albicans Candida species. J Med Microbiol. 44:399-408.

[3]. J. C. O. Sardi, L. Scorzoni, T. Bernardi, A. M. Fusco-Almeida, and M. J. S. Mendes Giannini, "Candida species: current epidemiology,pathogenicity, biofilm formation, natural antifungal

[4]. products and new therapeutic options," Journal of MedicalMicrobiology, vol. 62, no. 1, pp. 10-24, 2013

[5]. Sagarika Pradhan, S. Singh, M. P. Samal, R. Murthy, S. Pandey. "Characterization and Antifungal Susceptibility Pattern of Candida Spp. Isolated from Clinical Specimens". Journal of Evolution of Medical and Dental Sciences 2015; Vol. 4, Issue 40, May 18; Page: 7004-7012, DOI: $10.14260 /$ jemds/2015/1017

[6]. Dr Madhu sharma, june 2011,Candida blood stream infections in neonates, Rohtak, International journal of pharma \& bio sciences, volume 2 (2).

[7]. Tavleen Jaggi, A.D. Urhekar, Chitra Pai, Anahita Bhesania Hodiwala, Shalini Gore, Harpriya Kar; Study of Candida Species in Various Clinical Samples in a Tertiary Care Hospital: DHR International Journal Of Medical Sciences (DHR-IJMS) ISSN: 2278$831 \mathrm{X}$, Vol. 5(2), 2014

[8]. Mokaddas EM, Al-Sweih NA, Khan ZU. The species distribution andthe antifungal susceptibility of Candida bloodstream isolates in Kuwait:A 10 year study. J Med Microbiol 2007; 56: 255-9.

[9]. Lata R Patel, Jayshri D Pethani, Palak Bhatia, Sanjay D Rathod, Parul D Shah. Prevalence of Candida infection and its Antifungal susceptibility pattern in tertiary Care hospital, Ahmadabad. Nat J Med Res Vol. 2(4) 2012, 439-441

[10]. V. Manchanda, S.Agarwal, N.Verma. Yeast identification in routine clinical Microbiology laboratory and its clinical relevance.Indian Journal of Medical Microbiology 2011;29(2):172

[11]. Ragini Ananth Kashid, Sandhya Belawadi, GaytriDevi, Indumal.Characterisation and antifungal susceptibility testing for candida in a tertiary care hospital. Journal of Health Sciences \& Research; 2011;2(2):1-12

[12]. Arora D, Anand N, Goya G, Kumar R,Gupta P, Sarita. Prevalence and risk factors of Candida in cases of candidemia in a tertiary care hospital. International journal of pharmacy and pharmaceutical sciences 2011; 3(1):157-159.

[13]. Sagarika Pradhan, S. Singh, M. P. Samal, R. Murthy, S. Pandey. "Characterization and Antifungal Susceptibility Pattern of Candida Spp. Isolated from Clinical Specimens". Journal of Evolution of Medical and Dental Sciences 2015; Vol. 4, Issue 40, May 18; Page: 7004-7012, DOI: 10.14260/jemds/2015/1017

[14]. Shivanand Dharwad, Saldanha Dominic R.M SpeciesIdentification of Candida Isolates inVarious Clinical Specimens with Their AntifungalSusceptibility Patterns. Journal of Clinical and Diagnostic Research. 2011 November (Suppl-1), Vol-5(6): 1177-1181

[15]. Sunil kr Biradar, Amruthikishan,Gangane ,Sheeba, Amar N, Praveen D and Sreekantha,Prevalence and antifungal susceptibility of Candida species isolated from tertiary care hospital in North east,Karnataka, Int J Pharm Bio Sci 2013 Apr; 4(2): (B) 1113 - 1118.

[16]. Pfaller MA, Diekema DJ, Gibbs DL. Results from the ARTEMIS DISK Global Antifungal Surveillance Study, 1997 to 2007: a 10.5-Year Analysis of Susceptibilities of CandidaSpecies to Fluconazole and Voriconazole as Determined by CLSI Standardized Disk Diffusion. J Clin Microbiol. 2010; 48:1366-77.

[17]. R RI, K PN. Invitro susceptibilities of Candida isolates to Fluconazole and Voriconazole determined by disc diffusion in a tertiary carecentre, South India. Int J Res Health Sci [Internet]. 2014 Jul 31;2(3):783-6. 